\title{
Dynamic Stereoselection of Peptide Helicates and Their Selective Labeling of DNA Replication Foci in Cells
}

\author{
Jacobo Gómez-González, ${ }^{[a]}$ Yolanda Pérez, ${ }^{[b], \S}$ Giuseppe Sciortino, ${ }^{[c, d], \S}$ Lorena Roldan-Martín, ${ }^{[c]}$ \\ José Martínez-Costas, ${ }^{[e]}$ Jean-Didier Maréchal, ${ }^{[\mathrm{c}]}$ Ignacio Alfonso, ${ }^{[f]}$ Miguel Vázquez López, ${ }^{*},{ }^{[g]} \mathrm{M}$. \\ Eugenio Vázquez*,[a]
}

a Centro Singular de Investigación en Química Biolóxica e Materiais Moleculares (CiQUS), Departamento de Química Orgánica, Universidade de Santiago de Compostela, Spain. E-mail: eugenio.vazquez@usc.es

b NMR Facility, Institute of Advanced Chemistry of Catalonia (IQAC-CSIC), Jordi Girona 18-26, 08034 Barcelona, Spain.

c Departament de Química, Universitat Autònoma de Barcelona, 08193 Cerdanyola, Spain

d Dipartimento di Chimica e Farmacia, Università di Sassari, Via Vienna 2, I-07100 Sassari, Italy

e Centro Singular de Investigación en Química Biolóxica e Materiais Moleculares (CiQUS), Departamento de Bioquímica y Biología Molecular, Universidade de Santiago de Compostela, Spain.

f Department of Biological Chemistry, Institute of Advanced Chemistry of Catalonia (IQAC-CSIC), Jordi Girona 18-26, 08034 Barcelona, Spain

g Centro Singular de Investigación en Química Biolóxica e Materiais Moleculares (CiQUS), Departamento de Química Inorgánica, Universidade de Santiago de Compostela, Spain. E-mail: miguel.vazquez.lopez@usc.es

$\S \quad$ These authors contributed equally to this work.

\begin{abstract}
Peptide engineering has been extremely successful in creating new structures with defined properties and functions. Although generally overlooked in this context, coordination chemistry offers an additional set of interactions that opens unexplored design opportunities for developing complex molecular structures. With this in mind, we report the development of new artificial peptide ligands that fold into chiral and discrete supramolecular helicates in the presence of labile metal ions such as $\mathrm{Fe}(\mathrm{II})$ and $\mathrm{Co}(\mathrm{II})$. By selecting appropriate heterochiral $\beta$-turn promoting sequences, we can encode the stereoselective folding of the peptide ligand, and define the physicochemical properties of their corresponding metal complexes. The study of these metallopeptides by CD and NMR spectroscopy, combined with computational methods allowed us to identify and determine the structure of two isochiral $\Lambda \Lambda$-helicates, folded as topological isomers. We also show that these new peptide helicates, dynamically selected in the presence of labile Co(II) ions, can be locked as kineticallyinert species by in situ oxidation to Co(III). Finally, in addition to the in vitro characterization of their selective binding to three-way DNA, cell microscopy experiments demonstrated that a rhodamine-labeled Fe(II) helicate was internalized and selectively stains DNA replication factories in functional cells.
\end{abstract}

\section{Introduction}

Metal ions offer vast opportunities for the structural control at the molecular scale; exploiting their different coordinative properties, researchers can create complex assemblies of great beauty and unique properties, ${ }^{1}$ on par with the extraordinary structural and functional complexity displayed by designed peptides. ${ }^{2}$ Bridging the architectural potential of coordination chemistry with the structural predictability of peptide scaffolds would allow greater complexity in (supra)molecular designs by combining well-established peptide engineering concepts and tools with the supramolecular organization mediated by metal ions. ${ }^{3}$ Furthermore, the use of peptide ligands circumvents inefficient and labor-intensive multistep organic synthesis procedures typically associated with classic organic ligands, and simplifies the access to multiple variants required for optimization of the desired properties. ${ }^{4}$

Helicates are discrete metal complexes in which one or more organic ligands coil around-and coordinate-two or more metal ions. ${ }^{5}$ Helicates are inherently chiral species that can appear as two enantiomers, according to the orientation in which the ligands twist around the helical axis defined by the metal centers. Besides their intrinsic interest in supramolecular chemistry, ${ }^{6}$ helicates have shown exciting properties as antifreeze agents, ${ }^{7}$ or inhibitors of amyloid aggregation, ${ }^{8}$ as well as unique G-quadruplex and three-way DNA binding properties that result in promising antimicrobial and antitumoral activities. ${ }^{9}$ However, despite the efforts of many groups since the pioneering studies by Prof. Jean-Marie 
Lehn, ${ }^{10}$ helicates are still considered as rather exotic species. One of the major obstacles for the development of bioactive helicates is the complexity of their selective synthesis, particularly regarding to the control in their helicity, which hampers the efficient access to structural variants required for the screening and optimization of their biological properties. Notwithstanding some noteworthy examples that describe the stereoselective synthesis of chiral helicates, ${ }^{11}$ no general and straightforward strategy has yet been reported. Therefore, we decided to approach the stereoselective synthesis of helicates as a challenging model system to demonstrate the potential of peptide platforms for engineering metallo-supramolecular entities.

We have previously described the synthesis of a 2,2'-bipyridine (Bpy) amino acid derivative, ${ }^{12}$ and its incorporation into peptide ligands that predictably fold into coordination compounds with defined chirality in the presence of metal ions, including self-assembled helicates. ${ }^{13}$ Unfortunately, our original design featured two loops containing the hydrophobic $\beta$-turn sequence Pro-Gly, which made these ligands poorly soluble and prone to aggregation..$^{14}$ Moreover, these helicates, based on the kinetically labile $\mathrm{Fe}(\mathrm{II})$-trisbipyridine coordination, were inherently dynamic, which limited their detailed characterization and potential applications. Herein we describe the rational design of alternative oligocationic peptide helicates with improved solubility and thermodynamic stability, and the synthesis of kinetically inert $\mathrm{Co}$ (III) helicates through the oxidative modification of their dynamically assembled Co(II) precursors. We also show that these optimized self-assembled $\mathrm{Fe}(\mathrm{II})$ helicates bind to three-way DNA junctions in vitro and in functional cells, selectively labeling DNA replication foci in the cell nuclei.

\section{Results and Discussion}

\section{Rationale}

In order to improve the solubility of the peptide ligands (and that of the final helicates) we decided to replace the original $\beta$ turn modules, (D/L)-Pro-Gly, with more polar sequences that were also capable of inducing a reverse $\beta$-turn to direct the folding of the peptide chain into the desired three-stranded helicates. ${ }^{15}$ Based on the known tendency of heterochiral sequences to promote the formation of type $I I$ or type $I I^{\prime} \beta-$ turns, ${ }^{16}$ we focused our attention on the combination of residues with mixed chirality, D-D-L, or its mirror image $\mathrm{L}_{-} \mathrm{L}-$ $\mathrm{D}$, which were reported to increase turn formation and stability in short peptides. ${ }^{17}$ This pattern was very attractive for our purposes, because it allowed us great freedom in the choice of the residues in the loop, as long as they maintained their relative chirality in the sequence. Thus, in order to maximize the solubility, and considering the prevalence of Arg residues in protein-DNA complexes, ${ }^{18}$ as well as the known beneficial effects of arginine residues in DNA-binding helicates, ${ }^{19}$ we selected the sequences L-Arg-L-Pro-D-Arg and D-ArgD-Pro-L-Arg to define the $\beta$-turns and direct the folding of the peptide ligands into two enantiomeric peptide helicates, LLD and DDL respectively (Scheme 1). Additionally, we replaced the original O1PenBpy building block with a shorter $\beta$-Ala derivative $(\beta \mathrm{AlaBpy})$ to reduce the conformational freedom of the loops and therefore increase the thermodynamic stability of the assembled helicates.

\section{Synthesis and characterization of the peptide helicates}

The precursor peptide ligands LLD and DDL were obtained by standard Fmoc solid-phase peptide synthesis protocols. ${ }^{20}$ The Bpy ligands were introduced in the form of an Fmoc-protected building block, Fmoc- $\beta$ AlaBpy-OH (1, Scheme 1), which was synthesized with minor modifications of reported procedures reported for the synthesis of Fmoc-O1PenBpy-OH. ${ }^{12}$ The final peptide ligands were purified by HPLC, and their identity confirmed by mass spectrometry (See the Supporting Information). As expected, the presence of four charged arginine residues in the sequence made these new peptide ligands readily soluble in water, thus radically improving the poor solubility of our previous design. ${ }^{13}$
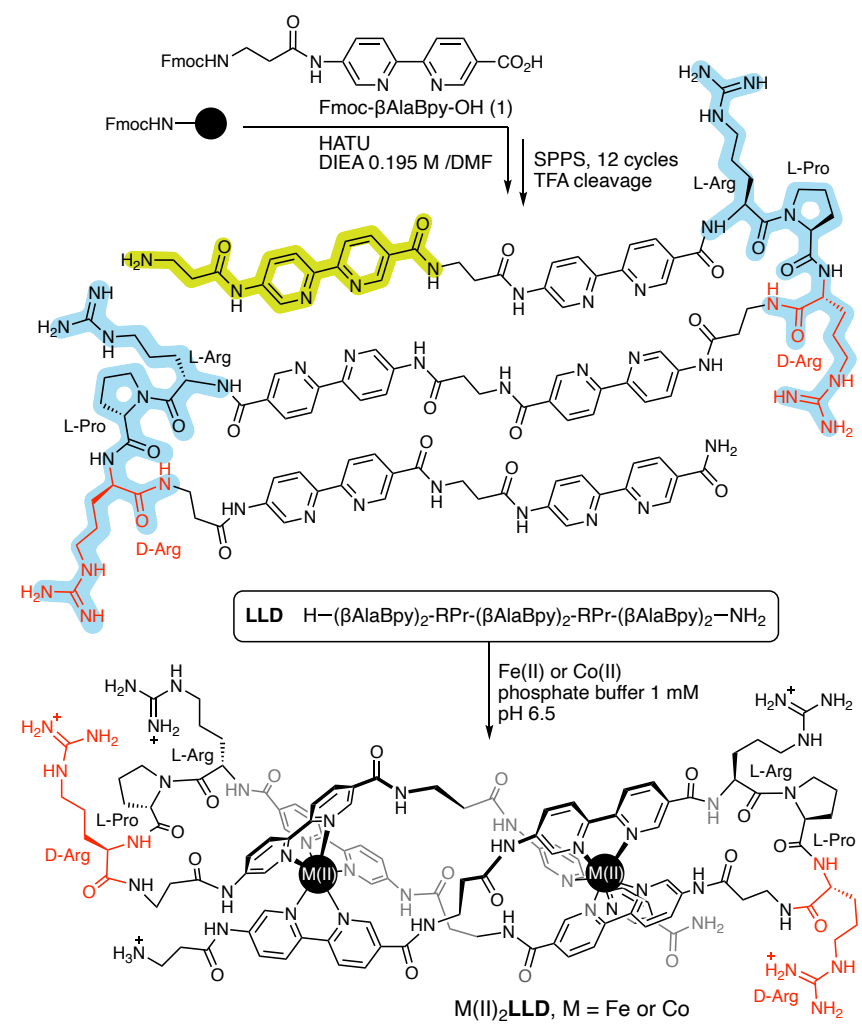

Scheme 1. Solid-phase peptide synthesis of the helicate ligand LLD using the Fmoc- $\beta$ AlaBpy-OH building block. $\beta$-turn sequences (RPr) are highlighted in light blue, and one $\beta A$ laBpy building block in green. After cleavage and purification, the helicate is stereoselectively folded under thermodynamic control in the presence of coordinating metal ions, $\mathrm{Fe}$ (II) or Co(II). The LLD ligand contains two loops featuring the heterochiral LArg-L-Pro-D-Arg sequence, while the DDL contains enantiomeric D-Arg-DPro-L-Arg loops (H-( $\left.\beta A l a B p y)_{2}-r p R-(\beta A l a B p y)_{2}-r p R-(\beta A l a B p y)_{2}-N_{2} H_{2}\right)$. Lamino acids are indicated in upper-case, and $D$-amino acids in lower case (i.e., R, P for L-Arg and L-Pro, and r, p for D-Arg and D-Pro).

Fluorescence titrations of the ligand LLD allowed us to characterize the assembly of the $\mathrm{Fe}(\mathrm{II})_{2} \mathrm{LLD}$ and $\mathrm{Co}(\mathrm{II})_{2} \mathrm{LLD}$ helicates in solution by monitoring the quenching of the $5^{\prime}-$ amido-[2,2'-bipyridine]-5-carboxamide unit in the $\beta$ AlaBpy building block upon metal coordination (Figure 1a). ${ }^{21,22}$ The resulting titration profile was successfully fitted to a 1:2 binding mode with dissociation constants of about 0.5 and $0.4 \mu \mathrm{M}$ for 
the first, and second metal ion coordination for both $\mathrm{Fe}(\mathrm{II})$ and Co(II). ${ }^{23}$ These values are two orders of magnitude smaller than those of the original O1Pen-based peptide helicates, ${ }^{13}$ demonstrating the beneficial effect of the reduced conformational freedom of the $\beta$ AlaBpy building block, which leads to new helicates with high thermodynamic stability in water. Furthermore, the observed positive cooperativity suggests that the coordination of the first metal ion further preorganizes the peptide for the binding of the second ion. MALDI spectra of the solutions at saturating concentrations of metal ions showed peaks at 2555.06 and 2561.02, consistent with the formation of the $\mathrm{Fe}(\mathrm{II})_{2} \mathrm{LLD}$ and $\mathrm{Co}(\mathrm{II})_{2}$ LLD helicates, respectively (See the Supporting information, Figure S22 and S24). As expected, the fluorescence titrations with the DDL ligand reproduced these results.

Importantly, the LLD and DDL peptide ligands displayed mirror image circular dichroism spectra. The $\mathrm{CD}$ was dominated by a strong Cotton effect band at c.a. $320 \mathrm{~nm}$, which pointed to a significant preorganization of the peptide chain and the effective chiral induction by the heterochiral $\beta$-turn modules in combination with $\Pi$-stacking interactions between the bipyridine units. ${ }^{12 a,}{ }^{24}$ Addition of $\mathrm{Fe}(\mathrm{II})$ ions to a LLD solution resulted in a large enhancement of the positive Cotton effect band at c.a. $320 \mathrm{~nm}$, as well as the appearance of a weaker negative Cotton effect band about $525 \mathrm{~nm}$, both bands consistent with the formation of a $\Lambda \Lambda$ - (or $M$ ) helicate (Figure 1b). Likewise, the enantiomeric peptide ligand DDL gave rise to opposite bands at 320 and $525 \mathrm{~nm}$, as expected for the induction of the mirror image $\Delta \Delta$ - (or $P$ ) helicate (Figure 1b). Taken together, these data are consistent with a dynamic process in which the mixture of the peptide ligands and the $\mathrm{Fe}(\mathrm{II})$ ions evolves towards the more stable folded helicates under thermodynamic control.
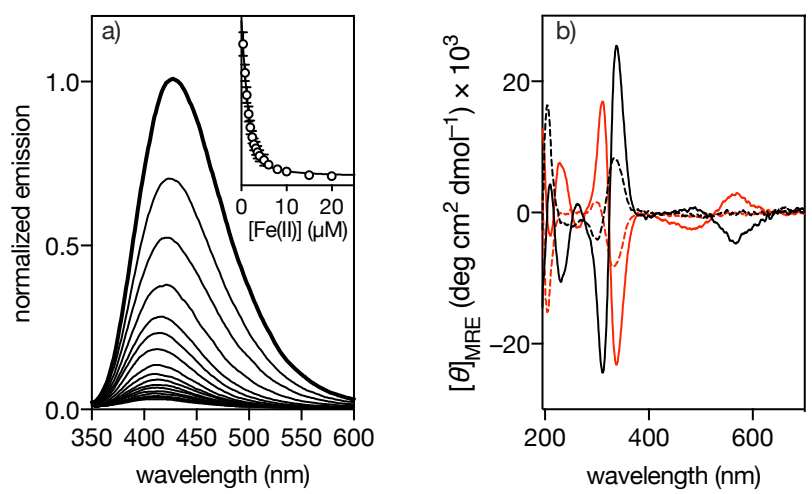

Figure 1. Titration of the LLD peptide ligand with Fe(II) ions. a) Normalized emission spectrum of a $2 \mu \mathrm{M}$ solution of LLD in $1 \mathrm{mM}$ phosphate buffer $\mathrm{NaCl} 10 \mathrm{mM}, \mathrm{pH} 6.5$ (thick line), and spectra of the same solution in the presence of increasing concentrations of Fe(II) ions (thin lines); inset showing the titration profile of three independent experiments and best fit to a one to two binding model (same range as main plot); b) circular dichroism spectra of $5 \mu \mathrm{M}$ solutions of LLD (black dashed line) and DDL (red dashed line) in $1 \mathrm{mM}$ phosphate buffer $\mathrm{NaCl} 10 \mathrm{mM}, \mathrm{pH}$ 6.5, and in the presence of $25 \mu \mathrm{M} \mathrm{Fe}(\mathrm{II})$ ions (same colors, continuous lines).

\section{Locking the dynamic equilibrium by oxidation}

The thermodynamic equilibrium between the $\mathrm{Fe}(\mathrm{II})$ ions and the peptide ligand in water media is fundamental for the correct folding and stereoselection of the helicate structure, but at the same time it introduces severe limitations in their potential applications and prevents their detailed structural characterization, because these self-assembled helicates are intrinsically dynamic and could disassemble, exchange ligands, or modify their structure or association state in response to changes in their environment. ${ }^{25}$ To overcome these limitations, a more robust and kinetically inert interaction was desirable. ${ }^{26}$ With this aim in mind, we tested the dynamic assembly of the peptide helicate in the presence of a labile Co(II) ions, followed by in situoxidation to form the corresponding kinetically-inert Co(III) derivative. This strategy has been described for the immobilization of His-tagged proteins on solid supports and surfaces, ${ }^{27}$ as well as for the assembly of kinetically-inert metal complexes, ${ }^{28}$ but, to our knowledge, has never been used in the case of artificial metallopeptides. Thus, a $600 \mu \mathrm{M}$ solution of LLD in milli-Q water was incubated with five equivalents of Co(II) ions. After $15 \mathrm{~min}$ of equilibration, the mixture was treated with ceric ammonium nitrate, $\left(\mathrm{NH}_{4}\right)_{2} \mathrm{Ce}\left(\mathrm{NO}_{3}\right)_{6}$, and analyzed by HPLC. Gratifyingly, while the labile helicates $\mathrm{Fe}(\mathrm{II})_{2} \mathrm{LLD}$ and $\mathrm{Co}(\mathrm{II})_{2} \mathrm{LLD}$ could never be observed in the acidic $\mathrm{RP}-\mathrm{HPLC}$ conditions $\left(0.1 \%\right.$ TFA $\left.\mathrm{H}_{2} \mathrm{O} / \mathrm{CH}_{3} \mathrm{CN}\right)$, we could isolate a new peak after oxidation with mass consistent with the formation of the $\mathrm{Co}(\mathrm{III})_{2} \mathrm{LLD}$ helicate, and a circular dichroism spectrum indicating the presence of species with the expected $\Lambda \Lambda$-chirality (Figure S27). ${ }^{29}$

\section{Structural determination of two helicate topoisomers}

The kinetic stability of this new $\mathrm{Co}(\mathrm{III})_{2} \mathrm{LLD}$ helicate allowed us to obtain high quality spectra, and the $1 \mathrm{D}{ }^{1} \mathrm{H}$ NMR spectra confirmed the folding of the peptide ligand into stable and ordered structures (Figure S4, Supporting Information), which encouraged us to pursue their structural characterization. Based on our previous work with metallopeptides and NMR studies of dinuclear ruthenium (II) polypyridyl complex, ${ }^{30}$ we decided to apply the standard approach for peptide sequence assignment and structural characterization, ${ }^{31}$ which consists in 2D NMR data acquisition in protonated solvent $\left(90 \% \mathrm{H}_{2} \mathrm{O} / 10 \% \mathrm{D}_{2} \mathrm{O}\right)$, proton/carbon resonance assignment and the use of the identified NOEs from the amino acid $/ \otimes \mathrm{Ala}$ residues to obtain distance restraints for molecular dynamics (See the Supporting Information for a more detailed description of this strategy, 1D/2D spectra and NOEs restraints).

To our surprise, the isolated fraction (single HPLC See Supporting Information) showed two main components in solution, isomers, $\mathbf{A}$ and $\mathbf{B}$, in slow exchange in the NMR chemical shift timescale (Figure 2). The resonances corresponding to $1 \mathrm{D}$ aromatic/amide region and $2 \mathrm{D}{ }^{1} \mathrm{H}-{ }^{1} \mathrm{H}$ NOESY correlations for $\mathrm{N} H-\otimes / \varangle \mathrm{C} H_{2}$ (in particular, for $\otimes-\mathrm{Ala} 3 / 5$ at helicate turns) revealed the conformational flexibility of the peptidic turns in the metal complex. In contrast, the region of the Bpy ligands coordinated to the metal ions is more rigid. For this reason, due to ${ }^{15} \mathrm{~N}$ T1 long relaxation times, the ${ }^{15} \mathrm{~N}$ bipyridine resonances could not be observed in the ${ }^{15} \mathrm{~N}-{ }^{1} \mathrm{H}$ HMBC spectrum (data not shown). Based on the NMR experimental data, ${ }^{32}$ and considering the similar coordination geometries of the $\mathrm{Co}$ (III) and $\mathrm{Fe}(\mathrm{II})$ trisbipyridyl complexes, we generated two reasonable starting point models of the Fe(II) isomers $\mathbf{A}$ and $\mathbf{B}$, and assessed their stability by Molecular Dynamics (MD) simulations in explicit solvent and periodic 
boundary conditions (See the Supporting Information for details). During the simulations, the helical twist of the helicates, as well as the octahedral coordination geometry of the $\mathrm{Fe}(\mathrm{II})$ metal centers with the Bpy units was conserved. The root-mean square deviation (RMSD) on the heavy atoms (excluding the side chains) was computed during the trajectories using the minimized initial structures as a reference. In both cases the trajectories stabilize after the first 25 ns, reaching relatively stable RMSDs of 1.5 and $2.5 \AA$ in average for isomers A and B, respectively. A cluster analysis performed on the full-length MDs showed a predominant geometry occupied about $64 \%$ and $89 \%$ of the total conformation repartition for A and B. Starting from the representative structures of these clusters, further molecular dynamics refinements where carried out along 60 additional ns under NOE's distance restraints (Tables S3 and S4) in explicit solvent. The NMR refinement was performed using SANDER including flat-bottom NOE-derived distance potential function. ${ }^{33}$ Overall, the results show that the two model structures, $\mathbf{A}$ and $\mathbf{B}$, are valid candidates consistent with the experimental observations (see Experimental Section for a detailed analysis). Helicates A and B are topoisomers, that is, they have the same chirality but different connectivity between the Bpy units around the metal centers. In isomer $\mathbf{A}$, the $\mathrm{N}$-terminal (blue, Figure 2) and the $\mathrm{C}$-terminal (red, Figure 2) bipyridine units are placed in the same side of the metallocylinder, whereas in isomer $\mathbf{B}$, both terminal Bpy units are disposed in opposite sides of the helicate. ${ }^{34}$

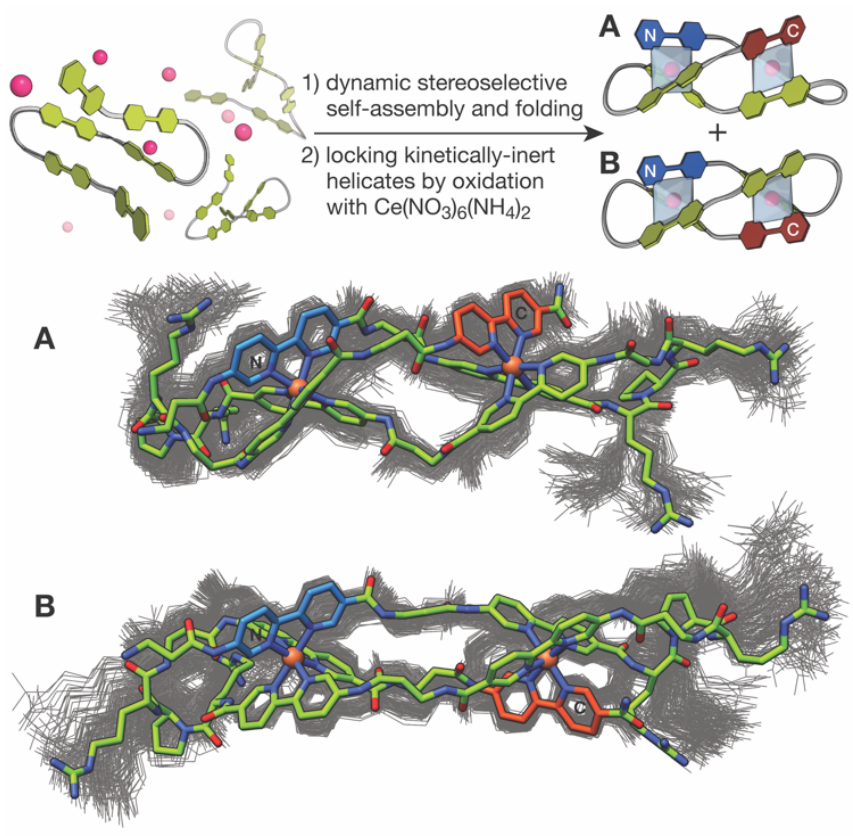

Figure 2. Top: assembly-followed-by-fixing approach for the construction of kinetically-inert Co(III) $)_{2}$ LLD peptide helicates. The initial dynamic selection under thermodynamic control is followed by the oxidation of Co(II) to Co(III) to yield kinetically-inert complexes A and B, which have the same chirality, but different topology. Bottom: representative structures for the $\mathrm{Fe}$ (II) helicates of the two most populated clusters of the MD trajectories (stick) together with 100 frames of each trajectory. N-terminal bipyridine in blue, and C-terminal bipyridine in red.

\section{The peptide helicates selectively recognize three-way DNA junctions in vitro}

Helicates are known to selectively interact with DNA threeway junctions by insertion into the hydrophobic cavity created by the surface of the base pairs at the center of the DNA junction..$^{9 \mathrm{~d}, 35}$ To study the DNA binding properties of these new peptide helicates we prepared a $2 \mu \mathrm{M}$ solution of a fluoresceinlabeled three-way junction DNA (Flu-twDNA), and measured its luminescence after the addition of successive aliquots of a solution of the preformed helicate $\mathrm{Fe}(\mathrm{II})_{2} \mathrm{LLD}$. The progressive quenching of the fluorescein emission at $515 \mathrm{~nm}$ could be fitted to a simple 1:1 binding mode (Flu-twDNA/Fe(II) ${ }_{2}$ LLD) with an apparent dissociation constant $K_{D} \approx 0.45 \mu \mathrm{M},{ }^{36}$ which is in line with the data obtained for the original Pro-Gly Fe(II) peptide helicate (Figure 3). ${ }^{13}$ Curiously, in the case of the $\mathrm{Co}(\mathrm{III})$ helicate, the titration profile of the emission intensity at $515 \mathrm{~nm}$ had to be fitted to a more complex model characterized by two different binding constants. A lower-affinity binding site, likely corresponding to the insertion of the $\mathrm{Co}(\mathrm{III})_{2} \mathrm{LLD}$ metallopeptide in the hydrophobic cavity, with a $K_{D} \approx 7.9 \mu \mathrm{M}$, and three equivalent higher-affinity sites $\left(K_{D} \approx 4.9 \mu \mathrm{M}\right)$, which based on reported $\mathrm{X}$-ray structures of related helicate/DNA complexes could correspond to nonspecific stacking interactions of the helicate with the blunt ends of the twDNA arms. ${ }^{9 \mathrm{~d}}$
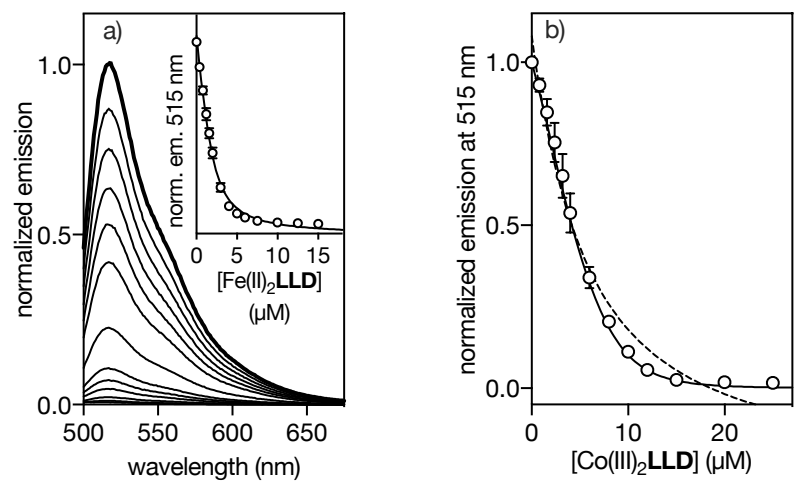

Figure 3. a) Normalized emission spectra of a titration of a $2 \mu \mathrm{M}$ solution of the fluorescein-labeled three-way junction DNA, Flu-twDNA, in $1 \mathrm{mM}$ phosphate buffer, $10 \mathrm{mM} \mathrm{NaCl}, \mathrm{pH} 6.5$ (thick line) with increasing concentrations of the Fe(II) $)_{2}$ LLD helicate (thin lines); inset: corresponding normalized titration profile of the fluorescein quenching at $515 \mathrm{~nm}$ and best fit to a one to one binding model; b) Normalized emission of a $2 \mu \mathrm{M}$ solution of the fluorescein-labeled three-way junction DNA, Flu-twDNA, in $10 \mathrm{mM}$ phosphate buffer, $100 \mathrm{mM} \mathrm{NaCl}, 10 \mathrm{mM} \mathrm{MgCl}$, $\mathrm{pH} 6.5$ with increasing concentrations of the $\mathrm{Co}(\mathrm{III})_{2}$ LLD; the best fit to a simple one to one binding model is shown as a dashed line, and the fit to a model including non-specific binding is shown as a continuous line. Titration data are the average of three independent experiments. Flu-twDNA, Y1Flu-5'TTTT CAC CGC TCT GGT CCT C-3'; Y2 5'-CAG GCT GTG AGC GGT G-3'; Y3 5'-GAG GAC CAA CAG CCT G-3'.

To better understand the interaction of the Fe(II) and Co(III) helicates with the DNA, we carried out electrophoretic mobility shift assays (EMSA) in polyacrylamide gel under nondenaturing conditions and using SYBRGold as the DNA stain. ${ }^{37}$ In agreement with the fluorescence studies, we found that incubation of twDNA with increasing concentrations of the 
preformed $\mathrm{Fe}(\mathrm{II})_{2} \mathrm{LLD}$ helicate resulted in the appearance of new slow-migrating band, consistent with the formation of the twDNA/Fe(II) ${ }_{2}$ LLD complex (Figure 4a). As expected for a high-affinity interaction, complete band shift is observed already at the lowest concentrations tested, and gives rise to a single new band with no smearing, even at high concentration of the $\mathrm{Fe}(\mathrm{II})_{2} \mathrm{LLD}$ helicate. On the other hand, no new slow-migrating bands were observed upon incubation of $\mathrm{Fe}(\mathrm{II})_{2} \mathrm{LLD}$ with a double-stranded DNA (dsDNA), which confirms the low affinity of this metallopeptide for regular BDNA (Figure 4b). In agreement with the fluorescence titrations, the EMSA assays showed reduced affinity of the Co(III) $)_{2}$ LLD helicate for the twDNA, so that the saturation of the twDNA is only observed at the highest concentrations of Co(III) ${ }_{2} \operatorname{LLD}(500$ $\mathrm{nM}$, Figure 4c). Remarkably, these assays also confirmed the tendency of the highly charged $\mathrm{Co}(\mathrm{III})_{2} \mathrm{LLD}$ helicate to form non-specific complexes, as shown by the disappearance of the dsDNA band upon incubation with this helicate (Figure 4d). ${ }^{38}$
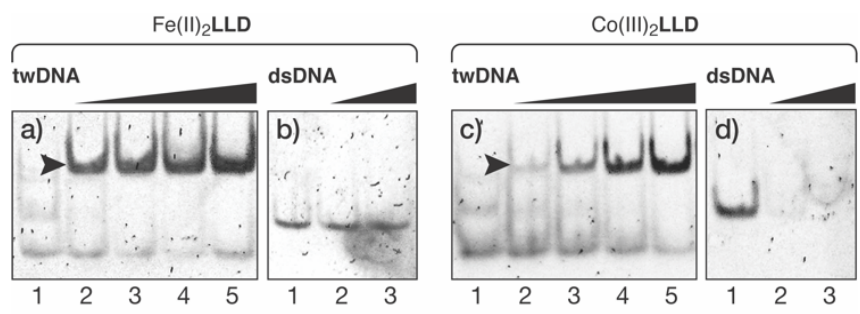

Figure 4. a) EMSA analysis of $200 \mathrm{nM}$ twDNA in the presence of $0,50,100$, $250,500 \mathrm{nM}$ of $\mathrm{Fe}(\mathrm{II})_{2}$ LLD. The new, slow-migrating band (indicated with an arrow), corresponds to the three-way DNA structure assembled in the presence of the $\mathrm{Fe}(\mathrm{II})$ helicate; b) $75 \mathrm{nM}$ dsDNA with 0, 1000, and $1500 \mathrm{nM}$ of Fe(II) $)_{2}$ LLD; gels in c) and d) correspond to the same concentrations of twDNA and dsDNA as a) and b) incubated with the same concentrations of the Co(III) ${ }_{2}$ LLD helicate (dsDNA 5'-AAC ACA TGC AGG ACG GCG CTT3'; twDNA, Y1-5'-CAC CGC TCT GGT CCT C-3'; Y2 5'-CAG GCT GTG AGC GGT G-3'; Y3 5'-GAG GAC CAA CAG CCT G-3').

We wondered about the molecular basis of the interaction between helicates and their biomolecular targets. Nonetheless, if the structural characterization of metallopeptides is per se a complex exercise for both experimental and theoretical approaches, the elucidation of 3D models of their complexes with other molecules is of the hardest challenges to face in this field. Still, we were able to obtain plausible models for the $\mathrm{Fe}(\mathrm{II})_{2} \mathrm{LLD}$ helicate threaded into the DNA three-way junction and predict possible differences between the two different species identified in our structural studies thanks to the novel GaudiMM platform: a molecular builder that is able to produce physically sound models of complex systems by exploring the conformational space that satisfies a series of molecular descriptors, uniquely adapted to perform flexible molecular docking experiments with large dimensional spaces to explore. ${ }^{39}$ The structures of the $\mathrm{Fe}(\mathrm{II})$ helicates extracted from the MD simulation under NOE constraints were docked to the DNA extracted from the X-ray structure reported by Hannon et al. of a helicate complex bound to the central cavity of a three-way DNA junction (PDB ID: 2ET0). ${ }^{9 \mathrm{~d}}$ Energetically preferred orientations of the helicates into the three-way DNA junction were only possible when the helicate side chains, as well as displacement of the twDNA along breathing modes of the entire DNA domains were taken into account (introduced into the calculations by including displacement along the ten lowest-energy normal mode vectors up to 2.5 Angstroms). These finding first showed that the accommodation of the helicates requires adaptation of the DNA target to the guests and that is lead to conformations slightly different to the unique $\mathrm{X}$-ray structure obtained to date. Calculations with the two different isomers also showed a better accommodation of isomer $\mathbf{B}$ into the three-way DNA cavity showing higher scoring and lower clashes respect to the isomer $\mathbf{A}$ (see Supporting Information for further details). No clear penalizing interactions between the three-way DNA junction and the helicate units are observed although the center of mass of B aligned better with the twDNA and the entire complex fits more deeply into the DNA receptor. This is likely related to the smaller volume of B and its slightly more stretched geometry (Figure 5 and S17).

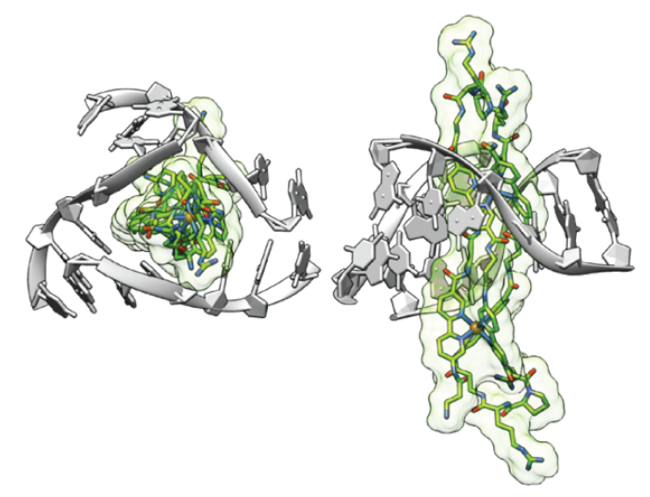

Figure 5. Lowest energy pose of isomer $\mathbf{B}$ of the Fe(II) $)_{2}$ LLD helicate in the central cavity of the twDNA. Left: top view showing the tight fit between the helicate and the twDNA hydrophobic site, which appears to be too narrow to comfortably accommodate isomer A. Right view of the same complex.

\section{A rhodamine-labelled Fe(II)-helicate selectively labels DNA replication sites in functional cells}

Having demonstrated the binding of these helicates to twDNA in vitro, we envisioned the application of these newly developed helicates to study these DNA structures in live cells. Preliminary experiments in which the rhodamine- and fluorescein-labeled LLD-derived $\mathrm{Fe}(\mathrm{II})$ helicates, $\mathrm{Fe}(\mathrm{II})_{2}$ (Rho-LLD) or $\mathrm{Fe}(\mathrm{II})_{2}$ (Flu-LLD), ${ }^{40}$ were incubated overnight with HeLa cells showed that these complexes remain trapped in endosomes (see Figure S28 in the Supporting information). ${ }^{41}$ However, if the cells were pretreated with Digitonin, ${ }^{42}$ then $\mathrm{Fe}(\mathrm{II})_{2}$ (Rho-LLD) was effectively internalized and showed in the red emission channel as a punctuated pattern in the cytoplasm and the nucleus (Figure 6a). Remarkably, the nuclear distribution of the helicate partially matched the localization of the DNA replication sites labeled with the proliferating cell nuclear antigen (PCNA) fused to GFP (Figure 6b), ${ }^{43}$ which demonstrates that the Fe(II) helicate is capable of targeting the three-way junctions transiently formed during DNA replication in vivo (Figure 6c). ${ }^{44}$ The staining of what appears to be the cell nucleolus is consistent with $\mathrm{Fe}(\mathrm{II})_{2}$ (Rho-LLD) binding to three-way RNA structures, which are also potential biological targets of helicates. ${ }^{45}$ To our knowledge, this is the first demonstration of in cellula twDNA staining with designed fluorescent probes. 

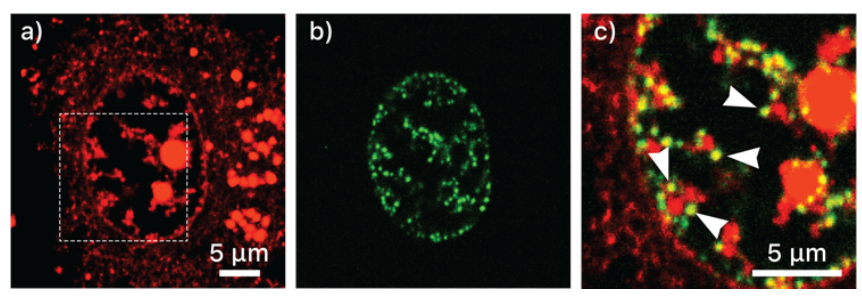

Figure 5. $\mathrm{Fe}(\mathrm{II})_{2}$ (Rho-LLD) selectively stains DNA replication sites. HeLa cells expressing protein GFP-PCNAL2 were incubated with $25 \mu \mathrm{g} / \mathrm{ml}$ Digitonin for $3 \mathrm{~min}$, then $5 \mu \mathrm{M}$ of Rho-LLD peptide ligand and $25 \mu \mathrm{M}$ of $\left(\mathrm{NH}_{4}\right)_{2} \mathrm{Fe}\left(\mathrm{SO}_{4}\right)_{2}$ for $30 \mathrm{~min}$. a) Red channel emission showing the distribution of the rhodamine-labeled helicate; b) green channel, corresponding to the emission of the GFP-PCNAL2 probe labeling the DNA replication foci; c) overlay of the green and red channels of the square region shown in a). Arrows highlight some of the foci where the staining of GFP-PCNAL2 and Fe(II) $)_{2}$ (Rho-LLD) overlap.

\section{Conclusion}

In conclusion, we have demonstrated that peptide design rules can be effectively applied to encode both structural and chiral information in de novo designed peptide ligands. In particular, we report new oligocationic peptide sequences containing bipyridine binding units that fold into three-stranded helicates in the presence of $\mathrm{Fe}(\mathrm{II})$ ions and bind with high affinity and specificity the central hydrophobic cavity of DNA three-way junctions. Furthermore, we have applied an assemblyfollowed-by-fixing method to obtain kinetically-inert $\mathrm{Co}$ (III) helicates. For the first time, we have determined the atomic structure of these peptide helicates by a combination of $\mathrm{CD}$, NMR and sophisticated computational methods, and applied a new theoretical approach to explore the nature of their DNA complexes. Finally, we also demonstrate that the $\mathrm{Fe}(\mathrm{II})_{2}$ (Rho-LLD) helicate binds to three-way DNA junctions in functional cells, selectively labeling DNA replication foci in the nuclei, thus demonstrating for the first demonstration the selective staining of three-way DNA in cellula with designed fluorescent probes.

\section{Acknowledgements}

Financial support from the Spanish grant RTI2018-099877-B100, the Xunta de Galicia (grupos con potencial de crecemento ED431B 2018/04, Centro singular de investigación de Galicia accreditation 2016-2019, ED431G/09, and ED431B 2018/04) and the European Union (European Regional Development Fund - ERDF) are gratefully acknowledged. J. G.-G. thanks the Spanish Ministry of Science and Innovation/Spanish Research Agency for his FPI fellowship. We also wish to express our gratitude to Soraya Learte-Aymamí for her assistance in the optimization of the EMSA assays. I. A. thanks Spanish Ministry of Science and Innovation/Spanish Research Agency (MCl/AEI/FEDER, RTI218-096182-B-I00, CSIC13-4E-2076) and AGAUR (2017 SGR 208). G.S. L.R.-M. and J.-D.M. thank Spanish MINECO (grant CTQ2017-87889-P) and the Generalitat de Catalunya (2017SGR1323). G.S., thanks Regione Autonoma della Sardegna (grant RASSR79857) for his postdoctoral fellowship. L. R.-M. thanks the Generalitat de Catalunya for her FI fellowship. plasmid GFP-PCNAL2 was generously provided by Dr. Cristina Cardoso. Molecular graphics with UCSF Chimera, developed by the Resource for Biocomputing, Visualization, and Informatics at the University of California, San Francisco, with support from NIH P41-GM103311. ${ }^{46}$

\section{Experimental Section}

Peptide synthesis. Peptides were synthesized on a Chem Matrix resin following standard solid-phase peptide synthesis protocols. Natural residues were coupled using $\mathrm{HBTU} / \mathrm{HOBt}$ ( 5 equiv) as coupling mixture and DIEA $0.2 \mathrm{M}$ in DMF $(4 \mathrm{~mL})$ as solvent. Non-natural $\beta A l a B p y$ residues were coupled using HATU (3.5 equiv) as coupling reagent and DIEA $0.2 \mathrm{M}$ in DMF ( $4 \mathrm{~mL}$ ) as solvent. Deprotection of the temporal Fmoc protecting group was performed with $20 \%$ piperidine in DMF for $15 \mathrm{~min}$. Cleavage/deprotection of the final ligands was performed by treatment of the resin-bound peptides for 2-2.5 $\mathrm{h}$ with $900 \mu \mathrm{L}$ TFA, $50 \mu \mathrm{L}$ DCM, $25 \mu \mathrm{L} \mathrm{H} \mathrm{H}_{2} \mathrm{O}$ and $25 \mu \mathrm{L}$ TIS $(1 \mathrm{~mL}$ of cocktail/40 $\mathrm{mg}$ resin). The crude products were purified by reverse-phase HPLC. HPLC was done using an Agilent 1100 series Liquid Chromatograph Mass Spectrometer system. Analytical HPLC was carried out using a Eclipse $X D B-C 18$ analytical column $(4.6 \times 150 \mathrm{~mm}, 5 \mu \mathrm{m}), 1 \mathrm{~mL} / \mathrm{min}$, gradient 5 to $75 \%$ B over 30 min (A: $\mathrm{H}_{2} \mathrm{O} 0.1 \%$ TFA, B: $\mathrm{CH}_{3} \mathrm{CN} 0.1 \%$ TFA). Purification of the peptides was performed on a semipreparative Phenomenex Luna-C18(250 $\times 10 \mathrm{~mm})$ reverse-phase column, $3 \mathrm{~mL} / \mathrm{min}$, gradient 10 to $50 \%$ B over $30 \mathrm{~min}$. ESI/MS was performed with an Agilent 1100 LC/MSD VL G1956A in positive mode.

Structural determination by NMR and MDs. Molecular dynamics (MD) simulations were set up with the xleap program solvating the helicates structures with a box of pre-equilibrated TIP3P water molecules, the total charge was balanced with chlorine ions (ions94.lib library). For the standard residues the amber99sb force field was used while for the Fe-bipyridines centers, the Fe-bonding force constants and equilibrium parameters, were obtained through the Seminario method, ${ }^{47}$ the GAFF force field was adopted for the remaining atoms. The point charges were derived using the RESP (Restrained ElectroStatic Potential) model. ${ }^{48}$ The force fields building operations were carried out using the MCPB.py. ${ }^{49}$ The solvent first and the whole system next, were submitted to 3000 energy minimization steps to relax possible steric clashes then, thermalization of water molecules and side chains was achieved by increasing the temperature from $100 \mathrm{~K}$ up to $300 \mathrm{~K}$. MD simulations under periodic boundary conditions were carried out during 100 ns with OpenMM engine. ${ }^{50}$ Restrained molecular dynamics were carried out with AMBER using SANDER Engine including flat-bottom NOEderived distance potential function. The weight of the restrains strength has been increased gradually in 2 ns steps. Clustering analysis was performed with cpptraj along all the trajectories considering all the heavy atoms.

Docking Studies. Docking studies were carried out with the GaudiMM platform, using the two Fe(II) helicate structures obtained from the clustering analysis as initial conformations, together with the unique crystallographic structure of a helicate bound to a DNA three way junction (PDB: 2ET0). ${ }^{\text {dd }}$ The original helicate was removed previous to docking. Global motions of the DNA strands were allowed through Normal Modes Analysis (NMA) setting a maximum displacement of $2 \AA$ along the 11 lowest energy modes, while the rotamers and torsions of the helicate were also considered. The GaudiMM genes used for the exploration included the finding of all the possible rotamers and torsions of the helicate. Moreover, the helicates were allowed full rotational in an evaluation sphere of $26.2 \AA$ from the centroid of the triplex core. Finally, the GaudiMM results were evaluated considering those displacements in term of genes (conformational exploration) and clashes as well as vina scores for the objectives. ${ }^{51}$ 
EMSA experiments. EMSAs were performed with a BioRad Mini Protean gel system, powered by an electrophoresis power supplies Power Pac Basic model, maximum power $150 \mathrm{~V}$, frequency $50-60 \mathrm{~Hz}$ at $140 \mathrm{~V}$ (constant $\mathrm{V}$ ). Binding reactions were performed over $35 \mathrm{~min}$ in $18 \mathrm{mM}$ Tris- $\mathrm{HCl}$ buffer ( $\mathrm{pH} 7.5), 90 \mathrm{mM} \mathrm{KCl}, 1.8 \mathrm{mM} \mathrm{MgCl} 2,9 \%$ glycerol, $0.11 \mathrm{mg} / \mathrm{mL}$ BSA, $2.2 \% \mathrm{NP}-40$ and $0.02 \mathrm{mM}$ of $\mathrm{ZnCl}_{2}$. In the experiments we used $75 \mathrm{nM}$ of the dsDNAs and $200 \mathrm{nM}$ of the twDNAs in a total incubation volume of $20 \mu \mathrm{L}$. twDNA was previously hybridized by mixing equimolar quantities of the different three strands (Y1, Y2, Y3) and heating the mixture at $90^{\circ} \mathrm{C}$ during $10 \mathrm{~min}$, followed by slow cooling until rt. dsDNA was also hybridized following the same procedure. Stock solutions of the $\mathrm{Fe}(\mathrm{II})_{2}$ LLD helicate were prepared by mixing the ligand $(0.5,1$ and $2 \mu \mathrm{M})$ and 5 eq of $\left(\mathrm{NH}_{4}\right)_{2} \mathrm{Fe}\left(\mathrm{SO}_{4}\right)_{2}$ in water followed by $15 \mathrm{~min}$ of stabilization. For the Co(III) $)_{2}$ LLD helicate, different stock solutions $(0.5,1$ and $2 \mu \mathrm{M})$ were prepared in water. After this, aliquots corresponding to the different lanes were prepared by mixing the corresponding DNA (twDNA or dsDNA) and different concentrations of the preformed helicates $\left(\mathrm{Fe}(\mathrm{II})_{2}\right.$ LLD or $\mathrm{Co}(\mathrm{III})_{2}$ LLD). After incubation for $30 \mathrm{~min}$ products were resolved by PAGE using a $10 \%$ non-denaturing polyacrylamide gel and $0.5 \times$ TBE buffer for $35 \mathrm{~min}$ at $20{ }^{\circ} \mathrm{C}$ and analyzed by staining with SyBrGold (Molecular Probes: $5 \mu \mathrm{L}$ in $50 \mathrm{~mL}$ of $1 \times$ TBE) for $10 \mathrm{~min}$ and visualized by fluorescence. $5 \times$ TBE buffer: $0.445 \mathrm{M}$ Tris, $0.445 \mathrm{M}$ Boric acid.

[1] a) W. M. Bloch, J. J. Holstein, B. Dittrich, W. Hiller, G. H. Clever, Angew. Chem. Int. Ed. 2018, 57, 5534-5538; b) J. J. Danon, A. Krüger, D. A. Leigh, J.-F. Lemonnier, A. J. Stephens, I. J. Vitorica-Yrezabal, S. L. Woltering, Science 2017, 355, 159-162; c) J.-F. Ayme, J. E. Beves, D. A. Leigh, R. T. McBurney, K. Rissanen, D. Schultz, Nat. Chem. 2012, 4 15-20; d) J. P. Leonard, P. Jensen, T. McCabe, J. E. O'Brien, R. D. Peacock, P. E. Kruger, T. Gunnlaugsson, J. Am. Chem. Soc. 2007, 129, 10986-10987; e) B. S. Pilgrim, D. A. Roberts, T. G. Lohr, T. K. Ronson, J. R. Nitschke, Nat. Chem. 2017, 9, 1276-1281; f) Y. Inokuma, M. Kawano, M. Fujita, Nat. Chem. 2011, 3, 349-358.

[2] a) E. G. Baker, G. J. Bartlett, K. L. Porter Goff, D. N. Woolfson, Acc. Chem. Res. 2017, 50, 2085-2092; b) B. Dang, H. Wu, V. K. Mulligan, M Mravic, Y. Wu, T. Lemmin, A. Ford, D.-A. Silva, D. Baker, W. F. DeGrado, Proc. Natl. Acad. Sci. USA 2017, 114, 10852-10857; c) H. Gradišar, S Božič, T. Doles, D. Vengust, I. Hafner-Bratkovič, A. Mertelj, B. Webb, A Šali, S. Klavžar, R. Jerala, Nat. Chem. Biol. 2013, 9, 362-366.

[3] a) E. Oheix, A. F. A. Peacock, Chem. Eur. J. 2014, 20, 2829-2839; b) Z. Zhou, G. Roelfes, Nature Catalysis 2020, 3, 289-294; c) S. M. MeierMenches, A. Casini, Bioconjug. Chem. 2020, 31, 1279-1288; d) A Jacques, C. Lebrun, A. Casini, I. Kieffer, O. Proux, J.-M. Latour, O. Sénèque, Inorg. Chem. 2015, 54, 4104-4113.

[4] a) Y. Inomata, T. Sawada, M. Fujita, Chem 2020, 6, 294-303; b) T. Sawada, Y. Inomata, K. Shimokawa, M. Fujita, Nat. Commun. 2019, 10 5687 ; c) K. A. Scheib, N. A. Tavenor, M. J. Lawless, S. Saxena, W. S. Horne, Chem. Commun. 2019, 55, 7752-7755; d) S. G. Bartual, J. M. Otero, C. Garcia-Doval, A. L. Llamas-Saiz, R. Kahn, G. C. Fox, M. J. van Raaij, Proc. Natl. Acad. Sci. USA 2010, 107, 20287-20292; e) M. R. Berwick, D. J. Lewis, A. W. Jones, R. A. Parslow, T. R. Dafforn, H. J Cooper, J. Wilkie, Z. Pikramenou, M. M. Britton, A. F. A. Peacock, J. Am. Chem. Soc. 2014, 136, 1166-1169; f) M. L. Zastrow, V. L. Pecoraro, Coord. Chem. Rev. 2013, 257, 2565-2588; g) Y. Lu, N. Yeung, N. Sieracki, N. M. Marshall, Nature 2009, 460, 855-862; h) H. Ishida, Y. Maruyama, M. Kyakuno, Y. Kodera, T. Maeda, S. Oishi, ChemBioChem 2006, 7, 1567-1570; i) M. Nitz, M. Sherawat, K. J. Franz, E. Peisach, K N. Allen, B. Imperiali, Angew. Chem. Int. Ed. 2004, 43, 3682-3685; j) M Albrecht, P. Stortz, P. Weis, Supramol. Chem. 2003, 15, 477-483.

[5] a) C. Piguet, G. Bernardinelli, G. Hopfgartner, Chem. Rev. 1997, 97, 2005-2062; b) M. Albrecht, Chem. Rev. 2001, 101, 3457-3498; c) M. Albrecht, Angew. Chem. Int. Ed. 2005, 44, 6448-6451.

[6] a) J.-F. Ayme, J.-M. Lehn, C. Bailly, L. Karmazin, J. Am. Chem. Soc. 2020, 142, 5819-5824; b) J.-F. Ayme, J. E. Beves, C. J. Campbell, D. A Leigh, Angew. Chem. Int. Ed Engl. 2014, 53, 7823-7827.

[7] D. E. Mitchell, G. Clarkson, D. J. Fox, R. A. Vipond, P. Scott, M. I. Gibson, J. Am. Chem. Soc. 2017, 139, 9835-9838.
Cell Internalization. HeLa cells were grown in monolayers in medium D-MEM supplemented with $5 \%$ fetal bovine serum (FBS), $2 \%$ L-glutamine and $1 \%$ antibiotic mix (penicillin and streptomycin) on glass bottom $35 \mathrm{~mm}$ dishes. Cell monolayers were transfected with plasmid pc653 using TransIT ${ }^{\oplus}$-LT1 (Mirus), ${ }^{43}$ according to the manufacturer's instructions and incubated at $37^{\circ} \mathrm{C} .24 \mathrm{~h}$ posttransfection, the cells were washed twice with cold transfer buffer (25 mM HEPES, $125 \mathrm{mM}$ potassium acetate, $2 \mathrm{mM}$ magnesium acetate, 5 $\mathrm{mM}$ sodium acetate, $1 \mathrm{mM}$ EDTA, $\mathrm{pH} 7.3)$, and permeabilized with $25 \mathrm{mg} / \mathrm{mL}$ Digitonin (Sigma) in the same buffer for $3 \mathrm{~min}$ on ice. Then, the cells were washed twice with transfer buffer containing $10 \mathrm{mg} / \mathrm{mL}$ of BSA and incubated in the same buffer with the preformed helicate ( $5 \mu \mathrm{M}$ Rho-LLD peptide ligand and $25 \mu \mathrm{M}\left(\mathrm{NH}_{4}\right)_{2} \mathrm{Fe}\left(\mathrm{SO}_{4}\right)_{2}$ ) for $30 \mathrm{~min}$, then washed again three times with the BSA-containing buffer, overlayed with D-MEM containing $10 \%$ FBS, and observed directly with no further processing. ${ }^{41}$ Confocal images were captured on an Andor Dragonfly spinning disk confocal system mounted on a Nikon TiE microscope equipped with a Zyla 4.2 PLUS camera (Andor). Images were processed either with Imaris (Oxford Instruments), or Adobe Photoshop CC (Adobe System, California, USA).

[8] a) Y. Guan, Z. Du, N. Gao, Y. Cao, X. Wang, P. Scott, H. Song, J. Ren, X. Qu, Sci Adv 2018, 4, eaao6718; b) M. Li, S. E. Howson, K. Dong, N. Gao, J. Ren, P. Scott, X. Qu, J. Am. Chem. Soc. 2014, 136, 1165511663.

[9] a) C. Zhao, H. Song, P. Scott, A. Zhao, H. Tateishi-Karimata, N. Sugimoto, J. Ren, X. Qu, Angew. Chem. Int. Ed. 2018, 57, 15723-15727; b) A. D. Faulkner, R. A. Kaner, Q. M. A. Abdallah, G. Clarkson, D. J. Fox, P. Gurnani, S. E. Howson, R. M. Phillips, D. I. Roper, D. H. Simpson, et al., Nat. Chem. 2014, 6, 797-803; c) R. A. Kaner, S. J. Allison, A. D. Faulkner, R. M. Phillips, D. I. Roper, S. L. Shepherd, D. H. Simpson, N. R. Waterfield, P. Scott, Chem. Sci. 2015, 7, 951-958; d) A. Oleksi, A. G. Blanco, R. Boer, I. Usón, J. Aymamí, A. Rodger, M. J. Hannon, M. Coll, Angew. Chem. Int. Ed. 2006, 45, 1227-1231; e) S. E. Howson, A. Bolhuis, V. Brabec, G. J. Clarkson, J. Malina, A. Rodger, P. Scott, Nat. Chem. 2012, 4, 31-36; f) X. Li, Z. Shi, J. Wu, J. Wu, C. He, X. Hao, C. Duan, Chem. Commun. 2020, 56, 7537-7548.

[10] B. Schoentjes, J.-M. Lehn, Helv. Chim. Acta 1995, 78, 1-12.

[11] a) T. Haino, H. Shio, R. Takano, Y. Fukazawa, Chem. Commun. 2009 2481-2483; b) W. Chen, X. Tang, W. Dou, B. Wang, L. Guo, Z. Ju, W. Liu, Chemistry 2017, 23, 9804-9811; c) N. Ousaka, Y. Takeyama, E. Yashima, Chem. Sci. 2011, 3, 466-469; d) M. Albrecht, K. Witt, H. Röttele, R. Fröhlich, Chem. Commun. 2001, 1330-1331.

[12] a) G. Rama, A. Ardá, J.-D. Maréchal, I. Gamba, H. Ishida, J. JiménezBarbero, M. E. Vázquez, M. Vázquez López, Chem. Eur. J. 2012, 18, 7030-7035; b) I. Gamba, G. Rama, E. Ortega-Carrasco, R. Berardozzi, V. M. Sánchez-Pedregal, L. Di Bari, J.-D. Maréchal, M. E. Vázquez, M. Vázquez López, Dalton Trans. 2016, 45, 881-885.

[13] I. Gamba, G. Rama, E. Ortega-Carrasco, J.-D. Maréchal, J. MartínezCostas, M. E. Vázquez, M. Vázquez López, Chem. Commun. 2014, 50, 11097-11100.

[14] a) S. R. Raghothama, S. K. Awasthi, P. Balaram, J. Chem. Soc. Perkin Trans. 2 1998, 137-144; b) A. Fragoso, P. Lamosa, R. Delgado, O. Iranzo, Chem. Eur. J. 2013, 19, 2076-2088; c) M. D. Shults, B. Imperiali, J. Am. Chem. Soc. 2003, 125, 14248-14249.

[15] A. M. C. Marcelino, L. M. Gierasch, Biopolymers 2008, 89, 380-391.

[16] a) G. D. Rose, L. M. Glerasch, J. A. Smith, in Adv. Prot. Chem. (Eds.: C.B. Anfinsen, J.T. Edsall, F.M. Richards), Academic Press, 1985, pp. 1-109; b) V. Brenner, F. Piuzzi, I. Dimicoli, B. Tardivel, M. Mons, Angew. Chem. Int. Ed. 2007, 46, 2463-2466.

[17] M. G. Bomar, B. Song, P. Kibler, K. Kodukula, A. K. Galande, Org. Lett. 2011, 13, 5878-5881.

[18] a) J. DeRouchey, B. Hoover, D. C. Rau, Biochemistry 2013, 52, 3000 3009; b) S. M. West, R. Rohs, R. S. Mann, B. Honig, J. Biomol. Struct. Dyn. 2010, 27, 861-866; c) C. Crane-Robinson, A. I. Dragan, P. L. 
Privalov, Trends Biochem. Sci. 2006, 31, 547-552; d) D. P. Mascotti, T. M. Lohman, Biochemistry 1997, 36, 7272-7279.

[19] L. Cardo, V. Sadovnikova, S. Phongtongpasuk, N. J. Hodges, M. J. Hannon, Chem. Commun. 2011, 47, 6575-6577.

[20] I. Coin, M. Beyermann, M. Bienert, Nat. Protoc. 2007, 2, 3247-3256.

[21] We have omitted the charges to avoid confusion between the formal charges of the helicates and the actual charges of the complexes including the Arg side chains and the $\mathrm{N}$-terminal ammonium.

[22] To our surprise, while the 2,2'-bipyridine ligand is known to be weakly emissive, and for all practical purposes considered non-fluorescent, the 5 '-amido-[2,2'-bipyridine]-5-carboxamide unit in the $\beta$ AlaBpy building block was highly emissive $(\Phi \approx 0.37)$. a) S. Dhanya, P. K. Bhattacharyya J. Photochem. Photobiol. A Chem. 1992, 63, 179-185; b) M. Yagi, T. Kaneshima, Y. Wada, K. Takemura, Y. Yokoyama, J. Photochem. Photobiol. A Chem. 1994, 84, 27-32.

[23] a) P. Kuzmic, Anal. Biochem. 1996, 237, 260-273; P. Kuzmič, in Methods Enzymol., Academic Press, 2009, pp. 247-280.

[24] J. M. Lehn, A. Rigault, J. Siegel, J. Harrowfield, B. Chevrier, D. Moras, Proc. Natl. Acad. Sci. U. S. A. 1987, 84, 2565-2569.

[25] W. M. Bloch, G. H. Clever, Chem. Commun. 2017, 53, 8506-8516.

[26] S. V. Wegner, J. P. Spatz, Angew. Chem. Int. Ed. 2013, 52, 7593-7596.

[27] a) S. Auer, L. Azizi, F. Faschinger, V. Blazevic, T. Vesikari, H. J. Gruber, V. P. Hytönen, Sens. Actuators B Chem. 2017, 243, 104-113; b) S. V. Wegner, F. C. Schenk, J. P. Spatz, Chemistry 2016, 22, 3156-3162; c) J. E. Hale, Anal. Biochem. 1995, 231, 46-49.

[28] a) H. Crlikova, J. Malina, V. Novohradsky, H. Kostrhunova, R. A. S. Vasdev, J. D. Crowley, J. Kasparkova, V. Brabec, Organometallics 2020 39, 1448-1455; b) M. J. Burke, G. S. Nichol, P. J. Lusby, J. Am. Chem. Soc. 2016, 138, 9308-9315; c) P. R. Symmers, M. J. Burke, D. P. August P. I. T. Thomson, G. S. Nichol, M. R. Warren, C. J. Campbell, P. J. Lusby, Chem. Sci. 2015, 6, 756-760; d) D. A. Leigh, P. J. Lusby, R. T. McBurney A. Morelli, A. M. Z. Slawin, A. R. Thomson, D. B. Walker, J. Am. Chem. Soc. 2009, 131, 3762-3771; e M. J. Burke, G. S. Nichol, P. J. Lusby, J. Am. Chem. Soc. 2016, 138, 9308-9315;) L. J. Charbonniere, G. Bernardinelli, C. Piguet, A. M. Sargeson, A. F. Williams, J. Chem. Soc. Chem. Commun. 1994, 1419-1420.

[29] Initial attempts at selective $\mathrm{Co}$ (II) to $\mathrm{Co}$ (III) oxidation using hydrogen peroxide were unsuccessful and resulted in complex product mixtures.

[30] S. D. Fairbanks, C. C. Robertson, F. R. Keene, J. A. Thomas, M. P. Williamson, J. Am. Chem. Soc. 2019, 141, 4644-4652

[31] K. Wüthrich, M. Billeter, W. Braun, J. Mol. Biol. 1984, 715-740.

[32] S. Sreekantan Nair Lalithambika, R. Golnak, B. Winter, K. Atak, Inorg. Chem., 2019, 58, 4731-4740.

[33] R. M. B. D.A. Case, W. Botello-Smith, D. S. Cerutti, T. E. Cheatham, III, T. A. Darden, R. E. Duke, T. J. Giese, H. Gohlke, A. W. Goetz, N. Homeyer, S. Izadi, P. Janowski, J. Kaus, A. Kovalenko, T. S. Lee, S. LeGrand, P. Li, C. Lin, T. Luchko, R. Luo, B. Madej, D. Mermelstein, K. M. Merz, G. Monard, H. Nguyen, H. T. Nguyen, I. Omelyan, A. Onufriev, D. R. Roe, A. Roitberg, C. Sagui, C. L. Simmerling, J. Swails, R. C Walker, J. Wang, R. M. Wolf, X. Wu, L. Xiao, D. M. York, P. A. Kollman, AMBER 16, 2016.

[34] Topological mirror images have previously been identified in proteins, but difficult to observe in small peptides, for which NMR data are often limited and lack well-defined secondary structure. a) J. K. Noel, A. Schug, A Verma, W. Wenzel, A. E. Garcia, J. N. Onuchic, J. Phys. Chem. B 2012 116, 6880-6888; b) K. A. Olszewski, A. Kolinski, J. Skolnick, Proteins 1996, 25, 286-299; c) A. Pastore, R. A. Atkinson, V. Saudek, R. J. Williams, Proteins 1991, 10, 22-32.
[35] a) J. Gómez-González, D. G. Peña, G. Barka, G. Sciortino, J.-D. Maréchal, M. Vázquez López, M. E. Vázquez, Front Chem 2018, 6, 520; b) C. R. K. Glasson, G. V. Meehan, J. K. Clegg, L. F. Lindoy, J. A. Smith, F. R. Keene, C. Motti, Chem. Eur. J. 2008, 14, 10535-10538.

[36] A similar effect has been reported recently in the binding of a selfassembled $\mathrm{Fe}(\mathrm{II})_{4} \mathrm{~L}_{4}$ tetrahedron to a three-way junction DNA: J. Zhu, C J. E. Haynes, M. Kieffer, J. L. Greenfield, R. D. Greenhalgh, J. R. Nitschke, U. F. Keyser, J. Am. Chem. Soc. 2019, 141, 11358-11362, and is consistent with energy transfer through the DNA bases between the fluorophores: a) K. Börjesson, S. Preus, A. H. El-Sagheer, T. Brown, B. Albinsson, L. M. Wilhelmsson, J. Am. Chem. Soc. 2009, 131, 42884293; b) A. Kuhlmann, L. Bihr, H.-A. Wagenknecht, Angew. Chem. Int. Ed Engl. 2020, 59, 17378-17382.

[37] a) L. M. Hellman, M. G. Fried, Nature Protocols 2007, 2, 1849-1861; b) D. Lane, P. Prentki, M. Chandler, Microbiol. Rev. 1992, 56, 509-528; c) R. S. Tuma, M. P. Beaudet, X. Jin, L. J. Jones, C. Y. Cheung, S. Yue, V. L. Singer, Anal. Biochem. 1999, 268, 278-288.

[38] The smearing and disappearance of bands at high concentrations has been attributed to the existence of multiple binding complexes and the precipitation of the DNA conjugates, see for example: a) E. K. Liebler, U. Diederichsen, Org. Lett. 2004, 6, 2893-2896; b) O. Vázquez, M. E. Vázquez, J. B. Blanco, L. Castedo, J. L. Mascareñas, Angew. Chem. Int. Ed. 2007, 46, 6886-6890; c) G.-X. He, K. A. Browne, A. Blasko, T. C. Bruice, J. Am. Chem. Soc. 1994, 116, 3716-3725; d) C. Portela, F. Albericio, R. Eritja, L. Castedo, J. L. Mascareñas, ChemBioChem 2007, 8, 1110-1114.

[39] J. Rodríguez-Guerra Pedregal, G. Sciortino, J. Guasp, M. Municoy and J.-D. Maréchal, J. Comput. Chem., 2017, 38, 2118-2126.

[40] Prepared in situ by mixing a $5 \mu \mathrm{M}$ Rho-LLD or Flu-LLD peptide ligand with $25 \mu \mathrm{M}\left(\mathrm{NH}_{4}\right)_{2} \mathrm{Fe}\left(\mathrm{SO}_{4}\right)_{2}$.

[41] We observed a drastic effect of the fluorophore in the internalization, so that the fluorescein-tagged helicate remains adsorbed to the plasma membrane, while the rhodamine derivative is internalized. Similar effects have been previously observed with metal complexes: C. A. Puckett, J. K. Barton, J. Am. Chem. Soc. 2009, 131, 8738-8739.

[42] Digitonin is a widely used additive used to transiently permeabilize the plasma membrane: a) M. Nishikawa, S. Nojima, T. Akiyama, U. Sankawa, K. Inoue, J. Biochem. 1984, 96, 1231-1239; b) M. P. Stewart, R. Langer K. F. Jensen, Chem. Rev. 2018, 118, 7409-7531.

[43] a) H. Leonhardt, H. P. Rahn, P. Weinzierl, A. Sporbert, T. Cremer, D. Zink, M. C. Cardoso, J. Cell Biol. 2000, 149, 271-280; b) R. Yokoyama, T. Hirakawa, S. Hayashi, T. Sakamoto, S. Matsunaga, Sci. Rep. 2016, 6, 29657.

[44] L. S. Shlyakhtenko, V. N. Potaman, R. R. Sinden, A. A. Gall, Y. L. Lyubchenko, Nucleic Acids Res. 2000, 28, 3472-3477.

[45] Phongtongpasuk, S. Paulus, J. Schnabl, R. K. O. Sigel, B. Spingler, M. J. Hannon, E. Freisinger, Angew. Chem. Int. Ed. 2013, 52, 11513-11516.

[46] E. F. Pettersen, T. D. Goddard, C. C. Huang, G. S. Couch, D. M. Greenblatt, E. C. Meng, T. E. Ferrin, J. Comput. Chem. 2004, 25, 16051612

[47] J. M. Seminario, Int. J. Quantum Chem., 1996, 6, 1271-1277.

[48] C. I. Bayly, P. Cieplak, W. Cornell, P. A. Kollman, J. Phys. Chem., 1993, 97, 10269-10280.

[49] P. Li, K. M. Merz Jr., Mcpb. Py: A python based metal center parameter builder. ACS Publications, 2016.

[50] P. Eastman, V. S. Pande, Comput. Sci. Eng. 2015, 12, 34-39.

[51] O. Trott, A. J. Olson, J. Comput. Chem. 2010, 31, 455-461. 